\title{
BMJ Open Photodiagnosis of genital herpes and warts within a specialist online sexual health service: an observational (mixed methods) study of user experience and clinical outcomes
}

\author{
Jessica Engen (D) , ${ }^{1}$ Adam Black, ${ }^{2}$ Gillian Holdsworth, ${ }^{1}$ Chris Howroyd, ${ }^{1}$ \\ Mollie Courtenay, ${ }^{1}$ Paula Baraitser (1) ${ }^{1}$
}

To cite: Engen J, Black A, Holdsworth G, et al. Photodiagnosis of genital herpes and warts within a specialist online sexual health service: an observational (mixed methods) study of user experience and clinical outcomes. BMJ Open 2021;11:e042160. doi:10.1136/ bmjopen-2020-042160

- Prepublication history and additional supplemental material for this paper are available online. To view these files, please visit the journal online (http://dx.doi.org/10.1136/ bmjopen-2020-042160).

Received 06 April 2021 Accepted 15 0ctober 2021

Check for updates

(C) Author(s) (or their employer(s)) 2021. Re-use permitted under CC BY-NC. No commercial re-use. See rights and permissions. Published by BMJ.

${ }^{1}$ Sexual Health, SH:24 CIC, London, UK

${ }^{2}$ Population Sciences and Environmental Health, King's College London, London, UK

Correspondence to

Dr Paula Baraitser;

paula_baraitser@mac.com

\section{ABSTRACT}

Objectives To evaluate the feasibility and acceptability of a pilot, free, online photodiagnosis service for genital herpes and warts with postal treatment delivered by a specialist digital sexual health service.

Setting An online sexual health service available free of charge in South East London, UK.

Participants Routinely collected data from 237 users of the pilot service during the study period and qualitative interviews with a purposive sample of 15 users. Intervention A pilot, free, online photodiagnosis service for genital herpes and warts with postal treatment delivered by a specialist digital sexual health service. Primary and secondary outcome measures Proportion of users who successfully uploaded photographs and the proportion diagnosed, treated and referred to face-to-face clinical services. User experience of this service.

Results The service was accessed by 237 users during the study period with assessment possible for $86 \%$ of users based on the photographs provided. A diagnosis of genital herpes or warts was made for $40.5 \%$ and $89.6 \%$ were subsequently treated through the service. Eighteen per cent were diagnosed as normal/not needing treatment and $42 \%$ were signposted to clinic for further clinical assessment.

Qualitative data showed that users felt able and willing to provide genital images for diagnosis. Those who were treated or reassured expressed high satisfaction with the service, valuing the convenience, discreetness and support provided. However, users, particularly those who required referral to other services requested more personal and detailed communication when a clinical diagnosis is given remotely.

Conclusions Findings suggest that online photodiagnosis was feasible and acceptable. However, effective and acceptable management of those who require referral needs careful remote communication.

\section{BACKGROUND}

Management of genital warts and herpes creates a significant workload for sexual health services (SHSs). In 2018, primary

\section{STRENGTHS AND LIMITATIONS OF THIS STUDY}

$\Rightarrow$ This is the first study on of 'online only' photodiagnosis of genital herpes and warts.

$\Rightarrow$ This study is timely because the demand for this service has increased significantly since access to face-to-face services has reduced as a result of COVID-19.

$\Rightarrow$ It offers a detailed account of the first year of operation of this service with important learning for those considering similar services.

$\Rightarrow$ Like all qualitative research, this element of the study offers in-depth accounts from small numbers of people and may not be representative of larger populations.

episodes of genital warts (57318 cases) and genital herpes (33 867) represented $21 \%$ of all new sexually transmitted infections (STIs) diagnosed in SHSs in England. ${ }^{1}$ Diagnosis and management of these conditions traditionally require an intimate examination and multiple clinic attendances which may be inconvenient, embarrassing and costly for service users. ${ }^{2}$ Costs are similarly high for SHSs due to the requirement for repeat clinic visits and clinician-administered treatment. ${ }^{34}$

Self-management of sexual health conditions through interactive, online services linked to clinical advice has an increasing evidence-base suggesting that it is both effective and acceptable ${ }^{56}$ and photodiagnosis has been pioneered within e-dermatology services. Benefits of online self-management and photodiagnosis include reduced opportunity costs for users (travel and time in clinics) and reduced health service costs. ${ }^{7}$ Several feebased services exist offering remote diagnosis and treatment for genital warts and herpes.

From October 2018, the National Health Service (NHS) commissioned, online SHS, 
SH:24 (www.SH24.org), offered a free, unadvertised, photodiagnosis service for genital warts and herpes to people over the age of 18 . Users provide information on their symptoms via an online form and upload up to four photographs of their lesions to receive a diagnosis from specialist sexual health clinicians including one photograph of the whole area affected to ensure that all relevant lesions are assessed. The online form was developed to collect the clinical information relevant to a diagnosis of genital herpes or warts through a process of user-led service design ${ }^{8}$ and includes an explanation of why the answer to each question is important (see online supplemental appendix 1 for an example). Users are asked specifically for information about symptoms that require further clinical assessment for example, changes in colour, bleeding with space to report anything that is concerning them. If appropriate, treatment is prescribed and posted to users through a UK-based registered pharmacy and remote specialist clinical support is offered through text/phone. If a diagnosis cannot be made, or if clinically indicated, users are signposted to face-to-face clinical care. Treatment information is provided in online supplemental appendix 2.

The aim of this study was to explore the feasibility and acceptability of the online photodiagnosis service using a mixed methodology in order to contribute to the limited evidence base on photodiagnosis for STIs. We were interested in the following questions:

1. Who uses an online photo-diagnosis and selfmanagement service for genital warts and herpes?

2. Are users able to take photographs of sufficient quality for remote diagnosis and what proportion of diagnoses can be made through photographs?

3. How is this service experienced by users with these conditions?

4. What combination of remote support would users value to support self-management and through what medium would they prefer this to be delivered?

\section{METHODS}

Routinely collected, anonymised data from SH:24's clinical records were extracted from all photodiagnosis orders received from January to December 2019. We described the users who completed the process of diagnosis and treatment and those signposted to face-to-face services. Information from the clinical records was used to understand the process of diagnosis including the reasons for signposting to clinic. We considered a diagnosis to have been made when a specialist sexual health clinician with more than 5 years experience of diagnosing and treating genital herpes and warts in face-to-face settings was confident that the following criteria were met:

1. The photographs uploaded were of sufficient quality to enable the lesion to be clearly seen

2. The lesions were sufficiently typical of either genital herpes or warts to make a diagnosis
Where there was any doubt that the lesions were typical of genital herpes or warts then the a referral to face-to-face care was made. This approach to diagnosis is consistent with that used in sexual health clinics, where genital warts and recurrent genital herpes (after previous episodes have been confirmed with laboratory testing) are diagnosed by experienced clinicians through a clinical examination. ${ }^{9}$ Users of the SH:24 photodiagnosis service can access free, online testing for chlamydia, gonorrhoea, HIV and syphilis.

Qualitative data were collected through semistructured interviews conducted by two different researchers (JE and $\mathrm{AB})$. JE is a public health trainee and $\mathrm{AB}$ is a sexual health nurse who has worked for the online service studied. A qualitative methodology was chosen in order to explore user perceptions and experience of the service with an iterative and inductive approach to analysis. Users who had registered to use SH:24's photodiagnosis service during the study period and had either been accepted into the service or reassured/signposted elsewhere were invited to take part. A purposive sampling method was used to ensure variability in participants in terms of their concern (warts or herpes) and whether they were treated, referred or reassured.

Users were recruited via an initial SMS sent by the researcher inviting them to participate in the study. A maximum of two follow-up texts were sent to nonresponders. Those who expressed an interest were sent further detailed information and given the opportunity to ask questions before deciding whether to take part. Interviews were conducted either face-to-face or via telephone, depending on the user's geographical location. Informed consent was obtained prior to the interview. Face-to-face interviews took place in a private room at a university. Prior to commencing the telephone interviews the interviewer confirmed that participants were in a suitable location where they felt comfortable. All participants were offered a gift voucher, which was worth $£ 30$ for a face-to-face interview and $£ 20$ for a telephone interview. The interview schedule is provided in online supplemental appendix 3.

Interviews were audio recorded and transcribed verbatim. Inductive thematic analysis was conducted by two researchers (JE and $\mathrm{PB}$ ). The transcripts were read and reread to enable the researchers to familiarise themselves with the data. These discussions referenced the researchers' relationship to the data including potential sources of bias ( $\mathrm{PB}$ is a NHS consultant and clinical director of the service studied). Themes were developed through this process and the data were coded according to these themes. Throughout this process the researchers met to discuss and revise the themes with two phases of coding development and revision completed. 
Table 1 Demographics of service users accessing the photodiagnosis service between January and December 2019

\begin{tabular}{|c|c|c|c|}
\hline & \multicolumn{2}{|c|}{ User's concern } & \multirow{2}{*}{$\begin{array}{l}\text { Total }(\%) \\
\text { Total orders } \\
237\end{array}$} \\
\hline & $\begin{array}{l}\text { Warts } \\
187(\%)\end{array}$ & $\begin{array}{l}\text { Herpes } \\
50(\%)\end{array}$ & \\
\hline Male & $86(46.2)$ & $11(21.6)$ & 97 (40.9) \\
\hline Female & $101(54.3)$ & $39(76.5)$ & $140(59.1)$ \\
\hline \multicolumn{4}{|l|}{ Ethnicity } \\
\hline White & $164(87.7)$ & $35(70)$ & $199(84)$ \\
\hline Black/African/Caribbean/ Black British & $8(4.3)$ & $5(10)$ & $13(5.5)$ \\
\hline Mixed/multiple ethnic groups & $8(4.3)$ & $8(16)$ & $16(6.8)$ \\
\hline
\end{tabular}

\section{Patient and public involvement}

A research priority setting exercise involving patients and the public prior to developing the research proposal based on two focus groups with service users that identified research into online service delivery as a priority topic for research on contraception. Intervention development involved service users through a process of human-centred design.

\section{RESULTS}

\section{Who uses photo-diagnosis services?}

There were 237 photodiagnosis orders (We have used the term 'order' to mean a request from a user for the photodiagnosis service) made to the service in 2019 (table 1). The majority of orders related to genital warts (79\%). Seventy-seven per cent of herpes orders were from females whereas the male/female split for genital warts orders was more even ( $46.2 \%$ vs $54.3 \%$, respectively). The average age of users was 27.4 years (range $18-50$ years).

The majority of users who were concerned about warts had not been previously diagnosed (68.4\%) (table 2). As a previous herpes diagnosis was a requirement of accessing the service most users concerned about herpes had been diagnosed previously $(76 \%)$. In line with the service protocol these users who had not been previously diagnosed were referred to their local sexual health clinic for confirmatory testing.

\section{What proportion of diagnoses can be made from photographs?}

Regarding the quality of photographs $37 \%$ of initial photographs sent were inadequate to make a diagnosis and further photographs were requested (table 2). In total, $86 \%$ of users provided photographs sufficient enough to make an assessment.

Forty per cent of the 237 orders resulted in a diagnosis of either genital warts or herpes and nearly $90 \%$ of these were treated through the service, with the remaining $10 \%$ referred to face-to-face services due to the lesions' location or presence of other symptoms. Nearly $18 \%$ of the 237 orders were diagnosed as normal/no treatment needed and were reassured or advised to monitor the lesion for change (figure 1).

Forty-two per cent of the 237 orders were signposted to clinic for face-to-face care, because, for example, lesions were neither herpes nor warts, for example a clinical diagnosis of another condition such as molluscum contagiosum was made $(15.2 \%)$; the user reported symptoms that required further investigation, for example lesions which change colour or bleed or because home treatment was contraindicated for example during pregnancy $(7.6 \%)$; or where there was no previous confirmation of a herpes diagnosis $(5.1 \%)$.

\section{Treatment}

The 86 care episodes where a diagnosis of genital herpes or warts was made required 100 prescriptions with 57 users treated once, 12 users twice and two users treated three times. Seventy-six per cent of prescriptions were for podophyllotoxin, $11 \%$ for imiquimod, $10 \%$ for aciclovir for episodic treatment and 3\% acyclovir for suppressive treatment. Users are routinely followed up to assess treatment progress, however, their response rate is low making it impossible to assess treatment success and subsequent clinic attendance.

\section{How is this service experienced by users with these conditions?}

Fifteen users took part in the interviews. Eight had been concerned about warts and seven concerned about herpes. Eight participants (four warts, four herpes users) were diagnosed and treated through the service, four were reassured and three signposted to clinic. Thirteen participants were female. 
Table 2 Photos and clinical information provided by service users accessing the photodiagnosis service between January and December 2019

\begin{tabular}{|c|c|c|c|}
\hline & \multicolumn{2}{|c|}{ User's concern } & \multirow{2}{*}{$\begin{array}{l}\text { Total (\%) } \\
\text { Total orders } \\
\mathrm{N}=237\end{array}$} \\
\hline & $\begin{array}{l}\text { Warts (\%) } \\
n=187\end{array}$ & $\begin{array}{l}\text { Herpes (\%) } \\
n=50\end{array}$ & \\
\hline Repeat photographs requested & $79(42.2)$ & $9(18)$ & $88(37.1)$ \\
\hline First diagnosis of herpes/warts* & $128(68.4)$ & $12(24)$ & $140(59.1)$ \\
\hline GP & $2(3.4)$ & $5(13.2)$ & $7(7.2)$ \\
\hline Self-diagnosed & $1(1.7)$ & $7(18.4)$ & $8(8.2)$ \\
\hline Other/not sure & $16(27.1)$ & $1(2.6)$ & $17(17.5)$ \\
\hline Symptoms of bleeding, itching or change in colour (warts only) & $52 / 187(27.8)$ & $\mathrm{n} / \mathrm{a}$ & - \\
\hline \multicolumn{4}{|l|}{ Outbreak frequency per year (herpes only) } \\
\hline Less than once & $\mathrm{n} / \mathrm{a}$ & $17(34)$ & - \\
\hline One to three times & $\mathrm{n} / \mathrm{a}$ & $10(20)$ & - \\
\hline Four to six times & $\mathrm{n} / \mathrm{a}$ & $11(22)$ & - \\
\hline More than six times & $\mathrm{n} / \mathrm{a}$ & $12(24)$ & - \\
\hline
\end{tabular}

\section{Understanding the problem}

Most users were unsure of the cause of their symptoms, delayed taking action and went online first to understand the problem using search engines, NHS websites and forums. Users sought a diagnosis and information on curability, transmission and treatments. Many users spent large amounts of time online with mixed results. Images of severe infections and alternative diagnoses such as malignancies generated anxiety and users struggled to find images of lesions similar to their own, including one user who searched for images of lesions on black skin. Some users sought opinions from friends or family. Most

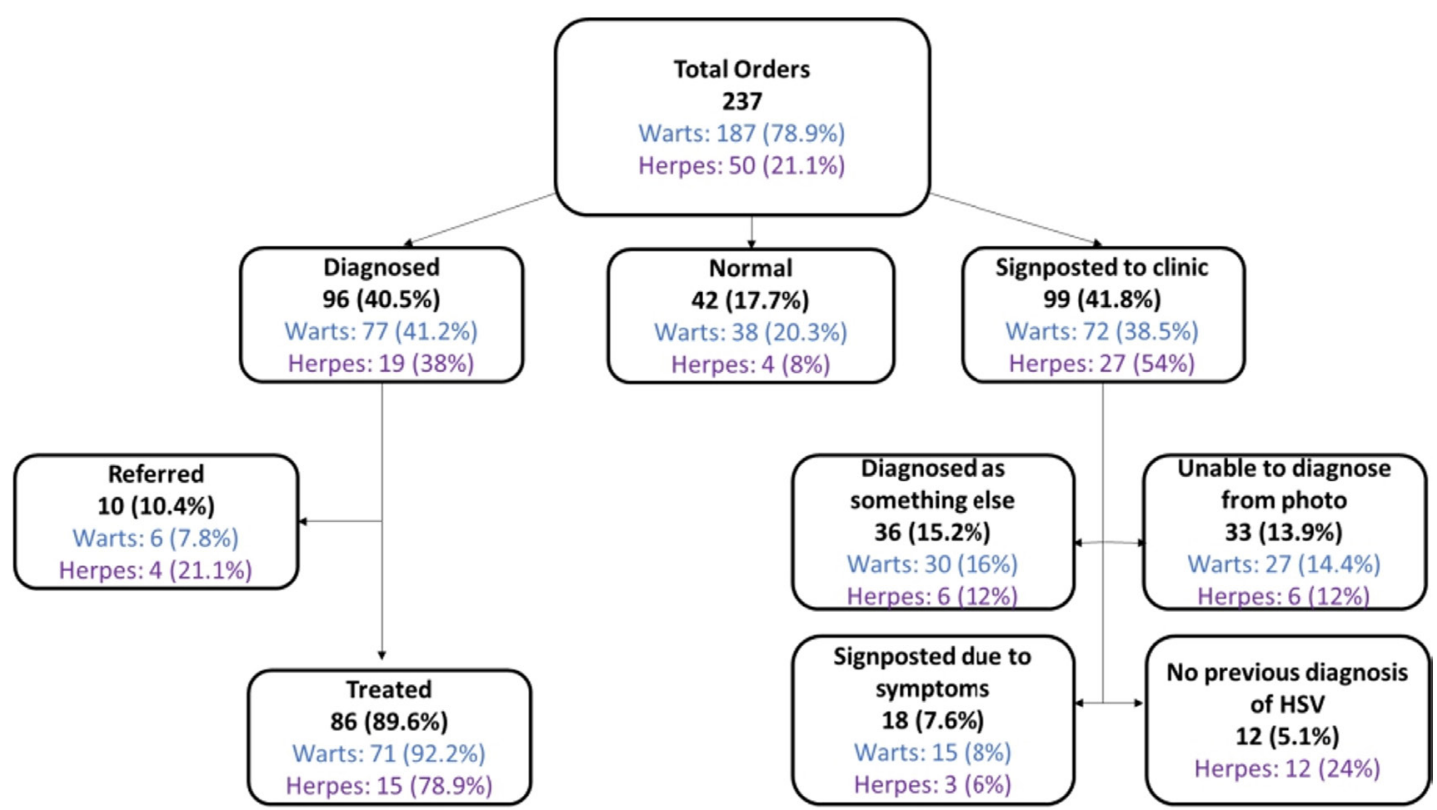

Figure 1 The pathways of service users accessing the photodiagnosis service January to December 2019. HSV, herpes simplex virus. 
Table 3 Reasons for choosing online

$\begin{array}{ll}\text { Rapid access from home } & \text { Users valued 'a quick fix' and to get the problem } \\ \text { sorted quickly that 'you can do it kind of at a } \\ \text { time and place and manner that's comfortable } \\ \text { for you'. }\end{array}$

Difficulty accessing

alternatives
Difficulty getting an appointment, not being able to or preferring not to take time of work or travel to get to a clinic
More discreet
Feeling that an online service would be more discreet, less shameful and less judgmental and that they could be more honest
'I think it's a lot better because you're sort of in your own space, which is more comforting than like being in a clinic room with a stranger who is going to tell you this'. Participant 3, female, reassured

'I mean you can do it whenever you like. So you can do it after work or at the weekend, whatever. So when I tried to go to [clinic], I had to take a morning off work. And it was kind of for nothing. So that was a bit like irritating, I guess. Whereas when I did, when I then went to SH:24, it was just, I think I did it after work one day. So it's just a lot easier and convenient'. Participant 1 , female, treated for warts

'I don't want to have to tell my friends where I'm going or tell work where I'm going'. Participant 5 , female, treated for herpes 'Yeah, you can be more honest. Cos you know like, you go to an STI clinic and you can get asked questions, and I know the majority of my friends will never tell the truth'. Participant 9, female, treated for herpes

STI, sexually transmitted infection.

were uncertain of their diagnosis and had unanswered questions after searching for information.

\section{Seeking a service/motivations for using an online service}

Users described difficulty accessing services. Several users accessed their general practitioner first and were then referred to a SHS or initially treated for something else before seeking a specialist opinion when symptoms remained. Users described difficulties with accessing SHS appointments, getting time off work and having to wait for long periods to be seen. Some specifically sought out online services and 'felt surprised and happy' that they existed. Some users felt attending a face-to-face service was not a viable option and would have been unlikely to seek help without an online option. There were three main motivations for deciding to use an online service to manage this episode: rapid access from home, difficulty accessing alternatives and discretion (table 3 )

Those with a history of multiple herpes outbreaks described wanting to self-manage and feeling more confident to do so. They wanted to avoid repeated clinic visits that were embarrassing, time-consuming and reminded them of their condition. As one user described they were, 'wanting to treat this in a way that, you know, impacts my life less and less'. Users with herpes also discussed the paradox of needing to start treatment early in the episode for it to be effective but not being able to access a clinic appointment quickly enough.

And then it doesn't feel like you know, you have genital herpes and you know, this is a part of your genital herpes journey going into the clinic every few months, to get your suppressive treatment. It's just like a constant reminder. - Participant 13, female, treated for herpes

\section{Views on taking and uploading photographs}

Very few users expressed concerns about data security and they were mainly confident about uploading photographs. These users expressed a sense of implicit trust and an assumption that their photographs would be secure. They assessed the ability of the service to provide the diagnosis and treatment requested, particularly the presence of health professionals who were knowledgeable or the clinical questions asked and from this they obtained the impression of a trustworthy service and made assumptions that data security was adequate.

I mean it never crossed my mind that 'oh this is going to get leaked' or anything like that. Or I could be identified by this... I did have trust and confidence in the service because there were follow-up messages. Participant 2, female, reassured

Others felt worried, concerned or awkward about the thought of taking and uploading photographs. Being affiliated with the NHS and staffed by medically trained professionals gave users more trust in the service, as well as information provided about data security, photograph storage and confidentiality. Some users were confident in the brand due to previous experience with the service and one user felt reassured by the presence of other online clinical services, feeling like remote diagnosis was becoming more commonplace.

Users described different ways in which they rationalised their decision to go ahead despite concerns. Some felt 
it was 'the lesser of two evils'. Although they found it embarrassing they felt it was better than seeing someone in person and preferred the anonymity of photographs. Some felt that although they still had concerns the need was greater and the lack of a viable alternative overrode their worries.

The physical aspects of taking the photos caused a lot of difficulty for users. Users described the process as awkward with the location of the lesions often making it difficult. Several discussed taking many attempts to get a good photograph and when asked by the service to send in new, clearer photos it lessened the convenience and benefits.

I find that the amount of times that I had to try to take those pictures and to get them online, I thought that was one of the biggest cons'. Participant 4, female, reassured

Users discussed having clearer instructions, tips on how to take good photos, and acknowledgement of the difficulties in taking the photos without help would have been beneficial.

\section{Receiving diagnosis and perceptions on the support available}

The majority of users who received a diagnosis and treatment highly valued the communication and support offered. Users felt that receiving a diagnosis 'in the comfort of their own home' was a benefit and they were positive about SMSs as the main form of communication. They were impressed with the immediacy of the contact and discussed feeling like it was a natural conversation and convenient means of communication.

Users who were signposted to clinic, however, expressed very different views. They felt there was no personal touch, felt unsure what to do next and one user expressed feeling more worried about their symptoms. Some users expressed strong emotions about having gone through the process of uploading photographs not to receive the benefit of a remote diagnosis describing feeling 'slightly violated' or 'exposed'. Users felt that more information on the clinical decision would have helped and that a phone call or face-to-face discussion would have allowed for a more in-depth discussion. However, some of the users who had not been able to access the service still felt reassured that the service was there and valued having an online clinical interaction even if the problem could not be resolved. Views were also mixed for those who were given a diagnosis of normal/no treatment needed. Some felt reassured and were pleased not to have 'wasted time at clinic', while others felt unsatisfied with the response and again wanted more information on how the diagnosis was reached.

The perceived lack of explanation about the clinical decision was seen as a downside to receiving the diagnosis by SMS as users described feeling more able to discuss/ ask questions in a face-to-face setting. They felt the loss of the nuance, non-verbal communication and ability for off-the-cuff remarks made it harder to obtain the information and reassurance they needed.

\section{Treatment and self-management}

All users who received treatment through the service were pleased with the experience. They described the process as easy, quick and discreet and felt they had enough information to support their use of the treatment.

it just seemed to have took a lot of stress out of what is ordinarily a stressful situation. Participant 5 , female, treated for herpes

Users were also pleased and impressed with the clinical support available and valued the follow-up messages received.

I was impressed by the level of communication - that I was getting messages asking how I was, how I was doing, had I received the medication, what my response was. - Participant 7 , female, treated for herpes

\section{DISCUSSION}

This observational study suggests that photodiagnosis of genital warts and herpes is feasible and acceptable. Effective assessment based on the photographs provided was possible for $86 \%$ of users and $54 \%$ were treated through the service, or advised no treatment was indicated, showing the potential impact photodiagnosis could have on reducing attendances in clinics. Like many services that are designed to identify and treat uncomplicated presentations of health conditions and refer complex presentations to more specialist care, an online photodiagnosis service may involve some users using the online service who are then referred to clinics. The costeffectiveness of this approach depends on the proportion who are referred to speclialist care and the relative cost of specialist care and online care. Our finding that $54 \%$ of users were treated online will inform future costeffectiveness analyses.

Our study found users described long journeys to seek information, diagnosis and support for their symptoms, often with multiple attempts and difficulties accessing services. This was particularly evident for users with herpes who described the difficulties, inconvenience and psychological impacts of trying to access regular, timely, support and treatment.

This is a small, observational study that describes one of the first publicly funded online services for the photodiagnosis of genital herpes and warts. Our findings are limited by the small size and its observational nature and the limited geographical area of the pilot.

Photodiagnosis may be an efficient response. Primary care professionals may be uncomfortable managing these conditions and referral rates to specialist services are high $^{3}$; however, access is limited. Tariffs for diagnosis and treatment of genital warts and herpes are high in clinics reflecting the clinical time taken to do an examination, 
for example UK estimates per consultation for warts or herpes are £112-£209.20 per episode. ${ }^{3}{ }^{10}$ In online services, some of this work is transferred to the user who invests time taking the photos and completing the self assessment. Clinical time can then be focused on diagnosis, prescribing and assessing response to treatment. Users need to be able, willing and adequately supported to take on this new responsibility and this may not be acceptable or possible for all service users and although initial work is reassuring ${ }^{6}$ more work is required on the accessibility of online services, particularly for vulnerable service users. ${ }^{11} 12$ The mean age of service users was 27 years which is a slightly older population than those diagnosed in sexual health clinics, where genital herpes and warts are most commonly diagnosed among people aged 20-241. This may suggest that younger people are less likely to access this service.

Despite some physical difficulties taking good quality photographs, users generally felt able, willing and trusting of the service to provide genital images for diagnosis. Those who were treated or reassured expressed high satisfaction with the service, valuing the convenience, discreetness and support provided. However, users, particularly those who required referral to other services, also expressed the importance of open, personal and detailed communication when a clinical decision is given remotely. This highlights the need for careful consideration of the communication and support provided to users requesting a remote diagnosis, recognising the increased psychological investment users have taken in providing intimate photographs and given that genital warts and herpes are highly emotive conditions. ${ }^{2}$ Close communication between online services and partner clinics would also facilitate transition from one service to another.

Contributors JE completed interviews and analysis and contributed to writing the paper. $\mathrm{AB}$ contributed to study design, completed interviews and contributed to writing the paper. $\mathrm{GH}, \mathrm{CH}$ and $\mathrm{MC}$ developed the service and contributed to study design. PB contributed to the conception and design of the study, oversaw data collection, contributed to data analysis, contributed to writing the paper and is the guarantor for the study.

Funding This study was funded by the Kings Health Partners Research and Development Challenge.

Competing interests $\mathrm{PB}, \mathrm{GH}$ and $\mathrm{CH}$ are directors of the online service studied. This work is part of a process of research on innovation at $\mathrm{SH}: 24$ where all innovation is the subject of research to ensure that learning is shared widely. $\mathrm{SH}: 24$ is a 'not for profit' organisation that provides health services to the National Health Service and sharing learning through innovation and research is one of the principles of the organisation.

Patient consent for publication Not applicable.

Ethics approval Ethical approval for the study was provided by London Fulham NHS Research Ethics Committee (Reference 18/L0/2007).

Provenance and peer review Not commissioned; externally peer reviewed.
Data availability statement Data are available upon reasonable request. The anonymised transcripts of the qualitative interviews collected in this study will be available to researchers upon reasonable request to the authors.

Supplemental material This content has been supplied by the author(s). It has not been vetted by BMJ Publishing Group Limited (BMJ) and may not have been peer-reviewed. Any opinions or recommendations discussed are solely those of the author(s) and are not endorsed by BMJ. BMJ disclaims all liability and responsibility arising from any reliance placed on the content. Where the content includes any translated material, BMJ does not warrant the accuracy and reliability of the translations (including but not limited to local regulations, clinical guidelines, terminology, drug names and drug dosages), and is not responsible for any error and/or omissions arising from translation and adaptation or otherwise.

Open access This is an open access article distributed in accordance with the Creative Commons Attribution Non Commercial (CC BY-NC 4.0) license, which permits others to distribute, remix, adapt, build upon this work non-commercially, and license their derivative works on different terms, provided the original work is properly cited, appropriate credit is given, any changes made indicated, and the use is non-commercial. See: http://creativecommons.org/licenses/by-nc/4.0/.

\section{ORCID iDs}

Jessica Engen http://orcid.org/0000-0002-3259-0450

Paula Baraitser http://orcid.org/0000-0002-3354-6494

\section{REFERENCES}

1 PHE. Sexually transmitted infections and screening for chlamydia in England. Health Protection Report, 2018;Volume 13, number 19. Available: https://assets.publishing.service.gov.uk/government/ uploads/system/uploads/attachment_data/file/806118/hpr1919_stisncsp_ann18.pdf [Accessed 31 Mar 2020].

2 Bhatia N, Lynde C, Vender R, et al. Understanding genital warts: epidemiology, pathogenesis, and burden of disease of human papillomavirus. J Cutan Med Surg 2013;17 Suppl 2:S47-54.

3 Desai S, Wetten S, Woodhall SC, et al. Genital warts and cost of care in England. Sex Transm Infect 2011;87:464-8.

4 Coles VAH, Chapman R, Lanitis T, et al. The costs of managing genital warts in the UK by devolved nation: England, Scotland, Wales and Northern Ireland. Int J STD AIDS 2016;27:51-7.

5 WHO. WHO guideline: recommendations on digital interventions for health system strengthening, 2019. Available: https://www.who.int/ reproductivehealth/publications/digital-interventions-health-systemstrengthening/en/ [Accessed 7 Apr 2020].

6 Wilson E, Free C, Morris TP, et al. Internet-accessed sexually transmitted infection (e-STI) testing and results service: a randomised, single-blind, controlled trial. PLOS Med 2017;14:e1002479.

7 Tensen E, van der Heijden JP, Jaspers MWM, et al. Two decades of teledermatology: current status and integration in national healthcare systems. Curr Dermatol Rep 2016;5:96-104.

8 Trimble H. "How the Sexual Health: 24 service used GOV.UK patterns.", 2016. Available: https://gds.blog.gov.uk/2016/10/14/howthe-sexual-health-24-service-used-gov-uk-patterns/ [Accessed 21 Jan 2021].

9 Pathway Analytics. Integrated Sexual Health Tariff [Online]. Available: https://www.pathwayanalytics.com/sexual-health/296?Contract= London\%20ISHT\%202017/18\&Curr=STI\%20Intervention\%20B\& Pri $=\% 20 \% 20 \% 20 \% 2097.96 \&$ Add $=\% 20 \% 20 \% 20 \% 2082.74 \&$ Host $=0$ [Accessed 22 April 2020].

10 Estcourt C, Flowers P, Laidlaw R. How can we maximise the accessibility of STI/BBV self-sampling for people with mild learning disabilities? IUSTI 2019 European Congress oral presentation, 2019.

11 Barnard S, Free C, Bakolis I, et al. Comparing the characteristics of users of an online service for STI self-sampling with clinic service users: a cross-sectional analysis. Sex Transm Infect 2018;94:377-83.

12 British Association for Sexual Health and HIV.. Anogenital herpes, 2014. Available: https://www.bashh.org/guidelines 